\title{
Special Column on Shear Failure Test and Analysis of Concrete Structures
}

Shear resistance capacity analysis is a traditional bottleneck problem for the analysis and design of reinforced concrete structures. Along with the use of high performance materials and the geometrical layout optimization of concrete, rebars and other additives, the performance of reinforced concrete components and structures are continuously improved. The testing, modelling and analyzing research works are continuously conducted for the accurate computation and conservative design of the improved concrete components and structures. This special column discusses: the new schemes and instruments for the shear or shear-dominated failure tests; new observations of the monotonic or cyclic shear or shear-dominated failure modes of concrete components with new formula or new shape; new explanation of shear or shear-dominated failure mechanisms and resistance analysis models; numerical analysis results based on new elemental or constitutive models; recent recommendations and formulas for the more economic and reliable design. The following five contributions accepted in this issue address the different aspects of this topic and show the diversity of the researches on shear capacity test and analysis of concrete components.

The first paper by $\mathrm{Xu}$ et al. puts its focus on the investigation of the influence of web horizontal reinforcement on the shear behaviour of RC beams. They conducted a series of test on eleven RC beams and observed the crack patterns and failure modes of those test specimens. Based on the obtained shear capacity curves and their analysis, they found that: web horizontal reinforcement carries the axial tension force induced by shear force across the cross section; combination of web horizontal reinforcements and stirrups will delay the occurrence of critical diagonal cracks and increase the shear capacity. Therefore, the authors recommend the influence of web horizontal reinforcement to be considered in design codes.

Marí et al. investigated the shear strength of slender $\mathrm{RC}$ elements subjected to point or distributed transverse loads. They presented a mechanical model and the related design-oriented expressions for the shear strength assessment. Some key points of the model are: the shear transferred by the concrete compression chord is linearly dependent on the relative flexural neutral axis depth; the concrete chord contribution of beams with uniformly distributed loads can be considered equal to that obtained in the case of point loads. The researchers verified the expressions using the experimental results from the ACl-DAfStb databases. The presented application example is very detailed, which makes the paper a good reference for young researchers.

Schutte and Sigrist studied the force transfer from the webs of T-beams into the flanges based on the generalized stress field approach. The shear stress distribution expressions in the flange are derived, compared with Eurocode, and calibrated using some test results. Although no concluding findings are attained as the number of sufficiently documented tests is limited, some recommendations are offered at the end of the paper for the application of the proposed method.

Witarto et al. presents an experimental study on shear-critical RC columns under cyclic loads with various loading rates. Four typical short columns were tested and the horizontal force-displacement envelope curves are measured. The obtained curves show that the ultimate force and stiffness patterns are almost the same for those columns under different loading rates up to $5 \mathrm{~Hz}$. Further numerical simulation study in OpenSees presents the similar global cyclic force-displacement curve as that obtained from the experimental tests. This justified the combined use of the Fiber Beam-Column elements for simulating the bending behaviour of the column and the Quadrilateral PlaneStress elements; furthermore, the shear resistance is found to be sufficiently accurate for the prediction of cyclic behaviour of short RC columns.

The final paper by Labib et al. presents a set of tests to study the ultimate shear strength of slender prestressed concrete (PC) I-girders and the shear concrete contributions along with the increase of concrete strength. Different ultimate shear strength prediction formulas were computed and compared with the experimental test data. The study shows that the ACI-318 (2011) code provisions are overly conservative and the AASHTO LRFD (2010) code is unsafe for the ultimate shear strength assessment of $\mathrm{PC}$ beams using high strength concrete. The UH-Method seems to be the most promising one for the prediction of ultimate shear strength of PC girders with high strength concrete. 
Acknowledgements This special column is financially supported by the Project for Enhancing International Impact of China STM Journals 2013. Special acknowledgements are delivered to Prof. P. Marti from ETH Zurich, Switzerland, Prof. T. C. Hsu from Univ. of Houston, USA, for their kind advices and supports. The editors also want to deliver the acknowledgements to the reviewers; these are: Prof. W. Z. Chen from Tongji University, China; Prof. V. Sigrist from TUHH, Germany; Prof. M. Fernández Ruiz from EPFL (Lausanne), Switzerland; Prof. F. Biondini from Politecnico di Milano, Italy; Prof. A. Recupero from Universita degli Studi di Messina, Italy; Prof. Y. L. Mo from University of Houston, USA; Prof. Z. Sun from Tongji University, China; Prof. W. Liao from Taipei University of Technology, China; and Prof. J. G. Nie from Tsinghua University, China.

Guest Editors,

Y. L. MO

Professor, University of Houston, USA

J. G. NIE

Professor, Tsinghua University, China

V. SIGRIST

Professor, Hamburg University of Technology (TUHH), Germany

Executive Editor,

Z. SUN

Research Fellow, Tongji University, China

E-mail: sunzhi1 @ tongji.edu.cn

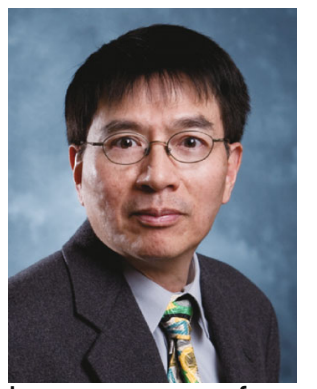

Y. L. MO received his MS degree from Taiwan University, Taipei, China and his Ph.D. degree in 1982 from the University of Hannover, Hannover, Germany. He was a structural engineer at Sargent and Lundy Engineers in Chicago, 1984-91, specializing in the design of nuclear power plants. After that, he was a professor at the Cheng Kung University, Tainan, China.

$\mathrm{He}$ is now the professor in the Civil and Environmental Engineering Department, University of Houston, and Director of the Thomas T.C. Hsu Structural Research Laboratory. Professor Mo has more than 27 years of experience in studies of reinforced and prestressed concrete structures subjected to static, reversed cyclic or dynamic loading. In addition to earthquake design of concrete structures, he is an expert in composite and hybrid structures. His outstanding research achievement is in the synergistic merging of structural engineering, earthquake engineering and computer application.

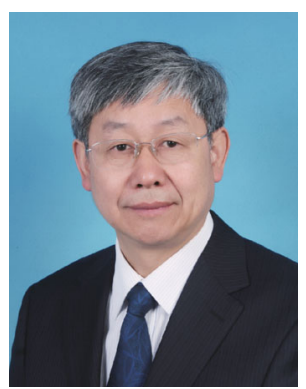

J. G. NIE received his Bachelor's Degree from Hunan University, China, his Master's Degree from Zhengzhou Institute of Technology, China, and his Doctor's Degree from Titograd University, Yugoslavia.

$\mathrm{He}$ is serving as a Professor of the Department of Civil Engineering, Tsinghua University, China. He is member of Chinese Academy of Engineering. He is currently holding the title of Chang Jiang Scholar, a high prestigious title awarded by the Chinese Ministry of Education. His major research interests are composite steel-concrete structures, innovative structural systems, and new rehabilitating technologies. He has more than 32 years of experience in research and directing students in these areas. He has been awarded the first prize of State Technological Invention Award, and Guang-Hua Engineering Science and Technology Award issued by Chinese Academy of Engineering.

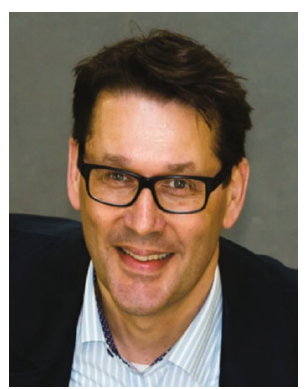

V. SIGRIST received in 1985 a bachelor's degree from Lucerne University of Applied Sciences and Arts, in 1988 a diploma in Civil Engineering and in 1995 a doctoral degree from Swiss Federal Institute of Technology (ETH), Zurich, Switzerland.

After having worked as an engineering consultant and expert in the field of bridge and structural engineering for several years, he was appointed Professor of Concrete Structures at Hamburg University of Technology, Germany, in 2002. His teaching includes basic and advanced courses in reinforced and prestressed concrete design as well as the conceptual design of structures. In research he is active in the fields of cracking behavior and minimum reinforcement requirements, shear analysis and design, structural assessment and strengthening of structures. $\mathrm{He}$ is a member of several German and international professional associations. Currently, he is the chairman of commission 2 of fib (International Federation for Structural Concrete). 